\title{
Effect of mechanical activation duration on combustion parameters of Al-Mg-based high-energy systems
}

\author{
Sergey Sokolov ${ }^{1}$, Yana Dubkova ${ }^{1, *}$, Alexander Vorozhtsov ${ }^{1,2}$, Valery Kuznetsov ${ }^{1}$, \\ Vladimir Promakhov ${ }^{1,2}$ and Ilya Zhukov ${ }^{1,2}$ \\ ${ }^{1}$ Tomsk State University, 36 Lenin Avenue, 634050 Tomsk, Russia \\ ${ }^{2}$ Institute for Problems of Chemical \& Energetic Technologies SB RAS, 1 Socialisticheskaya Street, 659322 Biysk, Russia
}

\begin{abstract}
The paper studies dispersion, oxidation degree, burning rate and combustion heat in high-energy mixtures obtained from of $\mathrm{Al}-\mathrm{Mg}$ powder materials depending on the duration of mechanical activation in a planetary mill. According to dispersion analysis by laser diffraction method, $3 \mathrm{~h}$ mechanical activation gives $\mathrm{Al}-\mathrm{Mg}$ particles with average particle size of $30 \mu \mathrm{m}$ compared to $180 \mu \mathrm{m}$ particles obtained after $2 \mathrm{~h}$ activation. Thermogravimetric analysis (TG) and differential scanning calorimetry (DSC) were used to record TG/DSC curves and measure burning rate and combustion heat for synthesized powders in comparison with engineered $\mathrm{Al}-\mathrm{Mg}$ powder PAM-4 (Novosverdlovsk Metallurgical Company, Yekaterinburg, Russia). It has been found that the injection of $6 \mathrm{~h}$ mechanically activated Al-Mg powder into high-energy compositions leads to 24 and $45 \%$ increase of burning rate and combustion heat compared to the compositions without additive.
\end{abstract}

\section{Introduction}

Modern high-energy materials (HEMs) consist of 3 main components: perchlorate and ammonium nitrate used as an oxidizer, polymer rubber as a fuel binder, and metal powders (aluminum, magnesium, beryllium, zirconium, boron, etc.) or their alloys as metal fuel. Fine-dispersed powders of metals mainly used as components for adjusting the burning rate and combustion heat of HEMs, which depend on the dispersion of introduced powders. In works [1-4], the effect of additives dispersion on the burning rate of HEMs compositions was described. Meanwhile, there are research showing that metal powder mechanical activation may improve thermophysical properties HEMs [5-10].

There are basic parameters used for powder selection in combustion study as scarcity, cost, combustion heat, burning rate, density and environmental friendliness of combustion products. The optimal components of highenergy systems providing basic complex of parameters are aluminum and magnesium. Aluminum powder is the most available and effective additive $(10 \ldots 20 \%)$ providing a high temperature of combustion [11-13], while magnesium provides easy ignition and high burning rate of HEMs compositions [13]. The alloys of the Al-Mg system ignite with lower ignition delays, lower temperatures and higher burning rates as compared to pure powders. At present, obtaining aluminum-magnesium powder (PAM) according to GOST 5593-78 from an alloy of aluminum and magnesium by spraying it into a sealed chamber is known. The fusion of technically pure aluminum and magnesium with further milling and mechanical activation in planetary mills can serve as an alternative. Mechanically activated particles have an increased reactivity, much easily enter into chemical reactions than powder mixtures obtained by other methods [14].

Despite the considerable interest in studying the effect of mechanical activation of eutectic alloys on the combustion parameters of high-energy systems, quantitative information about their burning rate, combustion heat, oxidation degree and other important parameters remains limited. In particular, there are practically no studies on integrated effect of duration and mode of mechanical activation on the combustion parameters of $\mathrm{Al}-\mathrm{Mg}$ system in the content of highenergy additives.

The purpose of this work is an experimental study of the properties such as dispersion, oxidation degree, burning rate and combustion heat in the composition of high-energy compositions obtained from of $\mathrm{Al}-\mathrm{Mg}$ powder materials depending on the duration of mechanical activation in a planetary mill.

\section{Materials and methods}

In our experiments we prepared five HEMs compositions as shown in the table 1 .

Ingots of technically pure aluminum A0 (99.0 wt.\% of Al, Rusal, Moscow, Russia) and technically pure magnesium Mg-95 (99.95 wt. \% Mg, Ruskhim, Moscow, Russia) in the mass ratio of 1:1 were used to obtain Al- 
$\mathrm{Mg}$ alloy additives which added after to traditionally used HEMs. Powders mixture in the weight ratio of 1:1 $[8,9]$ was mechanically activated in a chamotte-graphite crucible of a planetary mill (AktivNano, Saint Petersburg, Russia). Mechanical activation is fully described in [14]. Balls from steel 40XC having a diameter of $9.5 \mathrm{~mm}$ were used as milling bodies. The mass ratio of the milling bodies to the powder mixture was 3:1. Mechanical activation of the material was carried out in argon medium with a preliminary evacuation. The treatment time of the powder mixture was $9 \mathrm{~h}$ with sampling in an hour.

Obtained additives after 2 and $7 \mathrm{~h}$ treatment were added to HEMs consisted of ammonium perchlorate powder (PHA) with a diameter of $160 \ldots 315 \mu \mathrm{m}$; divinyl rubber based on butadiene rubber and plasticized with transformer oil (SKDM-80); of black amorphous boron powder (B-99) with diameter of $13 \mu \mathrm{m}$ (Polema, Russia). Industrially produced Al-Mg powder PAM-4 with diameter $65 \mu \mathrm{m}$ (Novosverdlovsk Metallurgical Company, Yekaterinburg, Russia) was selected as a control for determining burning rate and combustion heat. Also we added the mixture of industrial powders (Al-Mg powder mixture) consisting of $50 \mathrm{wt} . \%$ of $\mathrm{Al}$ powder ASD-0 with diameter of $50 \mu \mathrm{m}$ (Rusal, Moskow, Russia) and 50 wt.\% of Mg powder MPF-4 (Ruskhim, Moskov, Russia) with size of $45 \mu \mathrm{m}$.

Calorimetric studies of HEMs compositions were carried out using a thermal analyzer of Mettler Toledo company (module TGA / SDTA 851) in the temperature range $25 \ldots 1200{ }^{\circ} \mathrm{C}$ at a heating rate of $50{ }^{\circ} \mathrm{C} / \mathrm{min}$ in air medium using an aluminum oxide crucible.

Dispersity material study for each hour of mechanical activation was carried out with the help of an Analysette 22 MicroTec Plus instrument (Fritsch company) using laser diffraction method in the range of $0.08 \ldots 2000 \mu \mathrm{m}$. The dispersing was performed in ethanol medium (concentration of particles was 10 vol. \%). The theory of Fraunhofer was used for calculating.

X-ray fluorescence analysis (XRF) was performed using a Shimadzu XRD 6000 X-ray diffractometer with filtered $\mathrm{CuK} \alpha$ radiation from 20 to 80 angular degrees with a step of 0.2 degrees. Qualitative phase analysis was made using the PDF 4+ database, as well as the full profile analysis program POWDER CELL 2.4.

Samples of a cylindrical shape having a diameter of $10 \mathrm{~mm}$ and a height of $30 \mathrm{~mm}$ were produced by pressing the powder mixture in fluoroplastic assemblies. The determination and calculation of burning rate and combustion heat was performed according to the methods presented in $[15,16]$. The burning rate of compositions was determined using high-speed digital video camera Citius Centurio C100 (Citius Imaging Ltd, Finland). Obtained in the combustion process of samples of the video files were processed using a software video processing "TimeLapse (Al Devs, Russia). For each composition we conducted at least three duplicate experiments.

Measurement of combustion heat was carried out using a calorimetric installation. A basic element of calorimetric installation was the calorimetric bomb of constant pressure. Samples was weighed and placed in a calorimeter bomb. In a vessel of a calorimeter installation poured distilled water, lowered a bomb and took water temperature the metastatic Beckmann thermometer allowing to receive a high precision of measurements. After the executed measurements ignition and step-by-step measurement of water temperature in a calorimeter was carried out and then the calculation of combustion heat.

Table 1. Composition of prepared HEMs.

\begin{tabular}{|c|c|c|c|c|c|}
\hline \multirow{2}{*}{ Component } & \multicolumn{5}{|c|}{ Content of components, wt. \% } \\
\cline { 2 - 6 } & $\mathbf{1}$ & $\mathbf{2}$ & $\mathbf{3}$ & $\mathbf{4}$ & $\mathbf{5}$ \\
\hline SKDM-80 & 10.5 & 10.5 & 10.5 & 10.5 & 11 \\
\hline PHA & 70.5 & 70.5 & 70.5 & 70.5 & 74 \\
\hline B-99 & 14.3 & 14.3 & 14.3 & 14.3 & 15 \\
\hline PAM-4 & 4.7 & - & - & - & - \\
\hline $\begin{array}{c}\text { Al-Mg powder } \\
\text { mixture }\end{array}$ & - & 4.7 & - & - & - \\
\hline $\begin{array}{c}\text { Al-Mg alloy } \\
\text { (after 2 h } \\
\text { treatment) }\end{array}$ & - & - & 4.7 & - & - \\
\hline $\begin{array}{c}\text { Al-Mg alloy } \\
\text { (after 7 h } \\
\text { treatment) }\end{array}$ & - & - & - & 4.7 & - \\
\hline
\end{tabular}

\section{Research results}

Obtained Al-Mg alloy additives (after $6 \mathrm{~h}$ activation) were compared with industrial powder PAM-4 via dispersion analysis. It has been demonstrated that particle size distribution (PSD) for the samples is 3...127 and $6 \ldots 127 \mu \mathrm{m}$ and an average size is $37.8 \mu \mathrm{m}$ and 65 $\mu \mathrm{m}$ for Al-Mg alloy and PAM-4, respectively (Fig.1).

According to laser diffraction method, PSD character strongly depends on the duration of the mechanical treatment: we see that the main peak on PSD curve moves to the left - to the side of smaller particles. For instance, the mode diameter is $551 \mu \mathrm{m}(5.8 \%), 80 \mu \mathrm{m}$ $(3.4 \%)$ and $50(3.2 \%)$, respectively, after treatment duration during 2, 4, and $7 \mathrm{~h}$ (Fig.2). Further it has been calculated that longer mechanical activation causes particles dispersing: the average particle size is 180 and $30 \mu \mathrm{m}$, respectively for 2 and $7 \mathrm{~h}$ activation (Fig.3). The data show that after $2 \mathrm{~h}$ of mechanical activation, the average particle size of powder mixture decreases sharply from $180 \mu \mathrm{m}(2 \mathrm{~h})$ to $50 \mu \mathrm{m}(3 \mathrm{~h})$.

The analysis of thermogravimetric data shows that exothermic peak of HEMs shifts to a zone of lower temperatures with an increase of mechanical activation duration. The PAM-4 oxidation degree was $77.65 \%$ at an exothermic peak of $550{ }^{\circ} \mathrm{C}$; the degree of powder oxidation after $2 \mathrm{~h}$ activation was $70.65 \%$ at an exothermic peak of $600{ }^{\circ} \mathrm{C}$; after $4 \mathrm{~h}$ mechanical activation was $77.31 \%$ at an exothermic peak of $520{ }^{\circ} \mathrm{C}$; after $7 \mathrm{~h}$ activation was $74.74 \%$ at an exothermic peak of $520{ }^{\circ} \mathrm{C}$ (Fig. 4). 


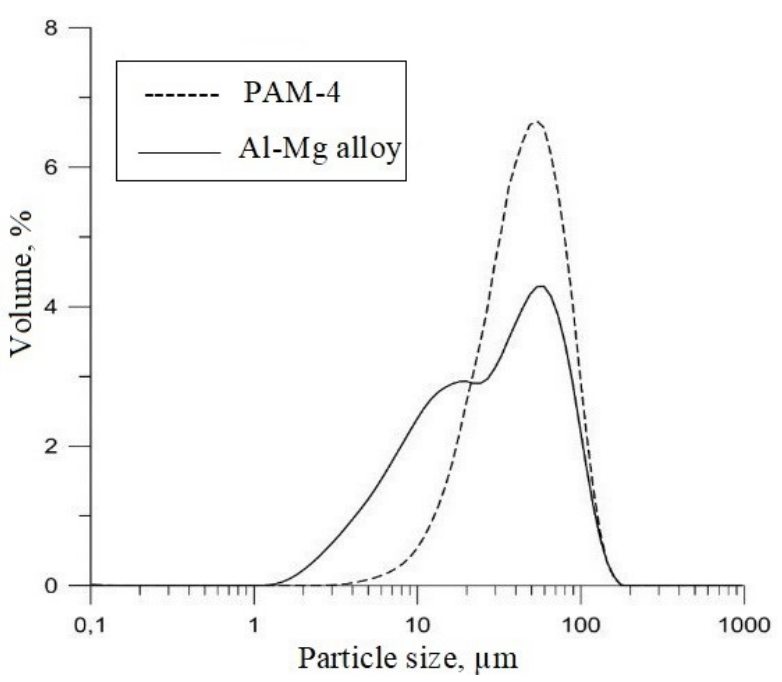

Fig. 1. Particle size distributions of PAM-4 compared to $\mathrm{Al}-\mathrm{Mg}$ alloy obtained by $6 \mathrm{~h}$ activation.

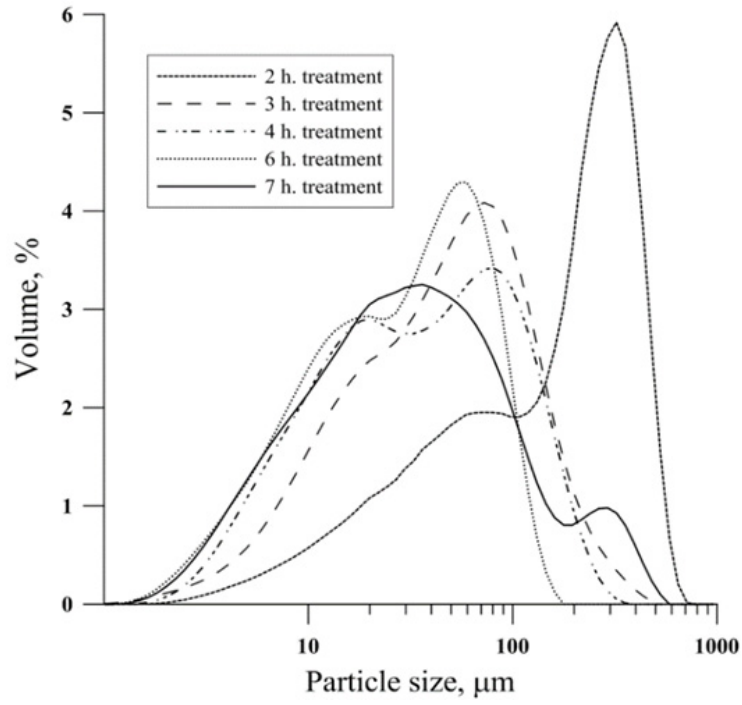

Fig. 2. Particle size distribution of $\mathrm{Al}-\mathrm{Mg}$ alloy additives obtained by mechanical activation.

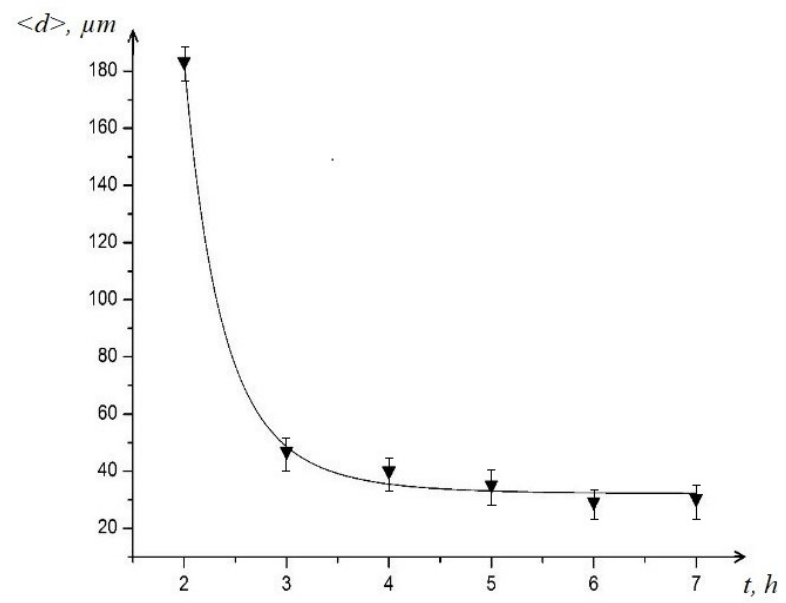

Fig. 3. Influence of mechanical activation duration $(t)$ on the average particle size (d).

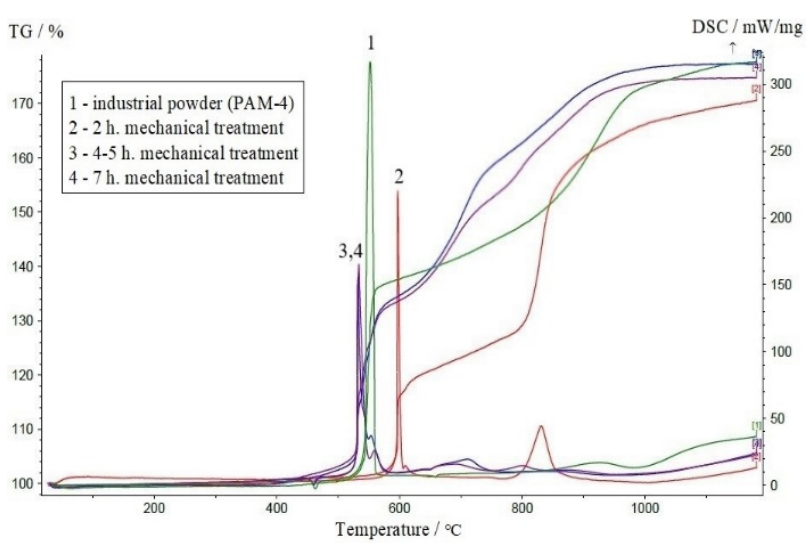

Fig. 4. Results of thermogravimetric analysis: 1-industrial aluminum-magnesium powder, 2-2 $\mathrm{h}$. mechanical treatment, 34-5 h. mechanical treatment, 4-7 h. mechanical treatment.

The DCS analysis (Fig.4) has shown that the addition of Al-Mg alloy additives to composition \#5 (SCDM-80 + ammonium perchlorate + amorphous boron) after $7 \mathrm{~h}$ activation leads to the growth of burning rate by $45 \%$ compared to the composition without the additive (Table 2).

Table 2. Burning rates and combustion heat of HEMs compositions.

\begin{tabular}{|c|c|c|c|}
\hline $\begin{array}{c}\text { HEMs } \\
\text { composition }\end{array}$ & $\begin{array}{c}\text { Density, } \\
\boldsymbol{\rho}\left(\mathrm{g} / \mathbf{c m}^{\mathbf{3}}\right)\end{array}$ & $\begin{array}{c}\text { Burning rate, } \\
\boldsymbol{u}\left(\mathbf{m m}^{-1} \mathbf{s}^{-1}\right)\end{array}$ & $\begin{array}{c}\text { Combustion } \\
\text { heat, } \boldsymbol{Q}\left(\mathbf{k a l}^{-1} \mathbf{g}^{-1}\right)\end{array}$ \\
\hline 1 & 1.44 & $2.28 \pm 0.2$ & $1710 \pm 17.1$ \\
\hline 2 & 1.47 & $2.06 \pm 0.2$ & $1762 \pm 18$ \\
\hline 3 & 1.47 & $2.17 \pm 0.2$ & $1745 \pm 22$ \\
\hline 4 & 1.47 & $2.47 \pm 0.2$ & $1765 \pm 13$ \\
\hline 5 & 1.47 & $1.71 \pm 0.2$ & $1432 \pm 12$ \\
\hline
\end{tabular}

The addition of mechanically activated Al-Mg alloy powder obtained during $7 \mathrm{~h}$ mechanical activation, to the HEMs increased the combustion heat by $24 \%$ compared to the composition \#5 - without a mechanically activated $\mathrm{Al}-\mathrm{Mg}$ powder. It has been established that the injection of a mechanically activated Al-Mg powder into the composition \#5 (SKDM-80 + ammonium perchlorate + amorphous boron), regardless of the mechanical treatment duration and dispersity does not affect the combustion heat.

\section{Conclusion}

We have shown the influence of mechanical activation duration on $\mathrm{Al}-\mathrm{Mg}$ alloy particles dispersion, and oxidation degree, burning rate and combustion heat in high-energy mixtures obtained with the addition of Al$\mathrm{Mg}$ powder materials of different origin as engineered $\mathrm{Al}-\mathrm{Mg}$ powders and mechanically activated Al-Mg alloy powders. It was established a significant reduction in particle sizes of Al-Mg alloy powder, particularly, from 180 to $30 \mu \mathrm{m}$ occurred, respectively after a $2 \mathrm{~h}$ and $3 \mathrm{~h}$ mechanical activation. The thermogravimetric analysis showed that the exothermic peak shifted to a zone of lower temperatures with an increase of mechanical 
activation duration and mechanical treatment for more than $4 \mathrm{~h}$ does not significantly affect the characteristics of the material.

It has been also stated that the injection of mechanically activated $\mathrm{Al}-\mathrm{Mg}$ powder into the composition containing SKDM-80, ammonium perchlorate, amorphous boron causes 1.4-fold growth of it's burning rate in air and 1.2- times increase of heat release of boron-containing high-energy compositions

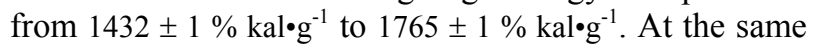
time, the dispersity of the injected Al-Mg powder does not have a significant effect on the heat release indices.

The researches related to the synthesis of Al-Mg system powders were carried out at the expense of the grant from the Russian Science Foundation (project No. 17-79-10272).

\section{References}

1. I.A. Zhukov, M.Kh. Ziatdinov, A.B. Vorozhtsov, A.S. Zhukov, S.A. Vorozhtsov and V.V. Promakhov, Russ. Phys. J. 59, 1324 (2016)

2. Y. Wang, T. Xu, L. Liu, Sci. Tech. Energetic Mater. 75, 21 (2014)

3. V.N. Popok, N.V. Boyarinova, Polzunovsky Vestnik [in Russian], 4-1, 67 (2010)

4. L.T. De Luca, L. Galfetti, F. Severini, L. Meda, G. Marra, A.B. Vorozhtsov, V.S. Sedoi, V.A. Babuk, Combust. Expl. Shock Waves, 41, 680 (2005)

5. B.S. Seplyarsky, N.A. Kochetov, R.A. Kochetkov, Chem. Sust. Dev. 20, 377 (2012)
6. A. Abraham, J. Obamedo, M Schoenitz, E.L. Dreizin J. Phys. Chem. Solids 83, 1 (2015)

7. L.I. Tsapalo, Yu.S. Naiborodenko, N.G. Kasatskiy and L.A. Arkatova, Chem. Sust. Dev. 20, 335 (2012)

8. Y. Aly, E.L. Dreizin, Comb. Flame 162, 1440 (2015)

9. Y. Aly, M. Schoenitz, E. L. Dreizin, Comb. Flame 160, 835 (2013)

10. A.G. Merzhanov, Solid Flame Combustion (Publishing House of Institute of Macrokinetics and Materials Sciences RAS, Chernogolovka, 2000)

11. W.Q. Pang, Luigi T.De Luca, X. H. Fan, X.Z. Fengqi, L. F. Xie, W.L. Yonghong, Int. J. Energ. Mater. Chem. Propuls. 14, 265 (2015)

12. M. V. Komarova, V. F. Komarov, A. G. Vakutin, A. V. Yashchenko, Polzunovsky Vestnnik [in Russian], 4-1,112 (2010)

13. V.G. Gopienko, S.Yu. Petrovich, V.P. Cherepanov, Metallic powders of aluminium, magnesium, titanium and silicon (TPU Publ. house, Tomsk, 2012)

14. G. Chernik, E. Fokina, N. Budim, M. Huller, V. Konchev, Nanoindustry, 5, pp. 32-35 (2007)

15. Ya. Dubkova, A. Zhukov, I. Zhukov, V. Promakhov, MATEC Web of Conferences, 110, 01022 (2017)

16. Ya. Dubkova, A. Zhukov, MATEC Web of Conferences, 92, 01068 (2017) 